\title{
Corrosão de refratários utilizados na siderurgia. Parte I: Propriedades microestruturais
}

\section{(Corrosion of refractories used in steel metallurgy. Part I: Microstructural properties)}

\author{
S. R. Bragança \\ DEMAT, Universidade Federal do Rio Grande Sul - UFRGS, Av. Osvaldo Aranha 99/705, Porto Alegre, RS 90035-190 \\ saulorb@ufrgs.br
}

\begin{abstract}
Resumo
Neste trabalho foi realizada uma revisão dos principais aspectos encontrados na literatura especializada sobre corrosão de refratários, avaliando-se a viabilidade de determinados ensaios e relacionando-os com resultados experimentais. O principal fator de desgaste dos refratários é considerado o ataque químico que o material sofre, porém ele é influenciado também por solicitações térmicas e mecânicas, sendo muitas vezes fatores concomitantes. O aumento da vida útil dos refratários enfrenta a compreensão de fenômenos complexos e depende de fatores operacionais, cujo controle e quantificação são difíceis no dia-a-dia da empresa, além das propriedades físicas e químicas dos refratários. Na abordagem proposta, mostram-se dados da investigação do desgaste corrosivo de refratários básicos, incluindo-se análise microestrutural, procurando relacionar os resultados experimentais com a perspectiva teórica da literatura.
\end{abstract}

Palavras-chave: refratários, corrosão, aciaria, escórias.

Abstract

In this study, main aspects found in the literature about refractories corrosion were reviewed, evaluating the feasibility of certain tests and relating them with experimental results. The main cause of refractories wear is considered the chemical attack that the material suffers, but it is also influenced by thermal and mechanical factors, often concomitantly. Increased life of refractories faces the understanding of complex phenomena and depends on operational factors, whose control is difficult in routine steel company processing. In addition the physical and chemical properties of refractories must be considered. In the proposed approach, research data of corrosive wear of basic refractories, including microstructural analysis, are related to the theoretical fundamentals found in literature.

Keywords: refractories, corrosion, steelmaking, slags.

\section{INTRODUÇÃO}

O consumo de refratários é parte significante do custo de produção do aço. Nos últimos anos, a produção anual de aço brasileiro foi de aproximadamente 33 milhões de toneladas, enquanto o consumo anual de refratários foi de $450 \mathrm{mil}$ toneladas $[1,2]$. As aciarias consomem em média entre 5 e $15 \mathrm{~kg}$ de refratário por tonelada de aço produzida, sendo grande parte deste consumo em refratários de panelas. O indicador de consumo específico de refratários ( $\mathrm{kg} /$ ton aço) em siderúrgicas brasileiras é compatível com os melhores valores mundiais [1]. A evolução na qualidade dos processos de aciaria demanda o aumento da qualidade dos materiais refratários, sejam eles de revestimentos ou de sede de válvula e plug, os quais podem ser fatores limitantes do ciclo de uma panela [3]. Portanto, em um mercado mundial competitivo e integrado é necessário um profundo conhecimento de refratários, para sua correta seleção e aplicação, como forma de reduzir os custos associados, garantido também maior vida útil dos mesmos em operação.
O desgaste de refratários é em geral um processo que ocorre gradualmente, tendo como principal fator à corrosão química e, em alguns casos, é fortemente acelerado devido a danos em conseqüência das oscilações térmicas. De acordo com o tipo de refratário empregado e a região em que o mesmo se encontra, o grau de corrosão química pode variar bastante na degradação do material. Fenômenos mecânicos também podem exercer considerável influência, como a erosão, abrasão e esforços de compressão, flexão e tração. Em geral, diz-se que a corrosão química inicia a degradação $\mathrm{e}$ as tensões térmicas e mecânicas levam à degradação final do tijolo [4]. A estrutura e as propriedades físicas do revestimento refratário são também fundamentais, assim como sua compatibilidade com as escórias. Estudos recentes mostram que o processo de infiltração de escória leva ao trincamento do refratário, com posterior deterioração do material e nova infiltração, de modo que este mecanismo acelera o desgaste do refratário, podendo inclusive prejudicar a qualidade do aço [5].

A velocidade das reações de corrosão vai depender das 
propriedades e concentrações dos reagentes (refratário e escória) e da temperatura, sendo também influenciada pela concentração de outras substâncias (impurezas) e pelas áreas das superfícies em contato. A taxa de reação vai depender da difusão dos reagentes, da velocidade da reação química e da velocidade de saída dos produtos da zona de reação. Estes conceitos bastante conhecidos no estudo das reações químicas aplicam-se bem ao estudo dos refratários. No entanto, o que torna difícil de compreender o processo de corrosão é o mecanismo intrínseco da corrosão, ou seja, a descrição detalhada da seqüência de etapas que determinam o grau e a velocidade de degradação do refratário, do qual se descobre quais fatores são mais relevantes.

Para a análise dos refratários, utilizam-se amostras provenientes do revestimento após o uso industrial do mesmo (post mortem) ou de testes de corrosão em laboratório. No primeiro caso, é difícil se conhecer com exatidão as condições do teste, como a composição química local, e no segundo, não se consegue simular plenamente as condições reais, como o perfil de temperatura através do revestimento. Foi enfatizado que as observações microscópicas e as análises são realizadas à temperatura ambiente e que não são representativas das fases minerais e vítreas existentes na alta temperatura de processo [6]. O uso de diagrama de fases e os cálculos de simulação termodinâmica fornecem valiosas informações em condições de equilíbrio, mas são limitados para a determinação das fases, pois não fornecem informações da cinética do processo [7]. Esse contexto cria evidentemente algumas barreiras para compreensão dos fenômenos de corrosão.

Repetidas vezes encontra-se na literatura que a corrosão de materiais refratários é complexa. Em face disto, no presente estudo procura-se mostrar os diversos aspectos envolvidos na corrosão de refratários, em uma série de artigos, iniciando-se pelas propriedades microestruturais. $\mathrm{Na}$ segunda parte desse estudo, serão abordadas as propriedades físico-químicas do revestimento refratário, analisandose também as condições operacionais e propriedades das escórias. Finaliza-se, com a caracterização de refratários comerciais, investigação detalhada na análise post mortem de refratários corroídos e perspectivas futuras em relação à redução do desgaste de material refratário. Assim, serão apresentados exemplos teóricos da literatura, discutindose a aplicação prática dos mesmos. Os principais exemplos são da siderurgia na produção de aços longos e especiais, principalmente de tijolos refratários magnésia-carbono e doloma-carbono, utilizados em forno panela.

\section{ANÁLISE DAS PROPRIEDADES MICROESTRUTURAIS}

A qualidade de um tijolo refratário vai depender diretamente da pureza de suas matérias-primas, da calcinação das mesmas e do processo de conformação. Estes fatores, assim como a qualidade de outros materiais adicionados, como ligantes, carbono e aditivos antioxidantes, vão ser à base da constituição da microestrutura de tijolos refratários

\section{Matérias-primas}

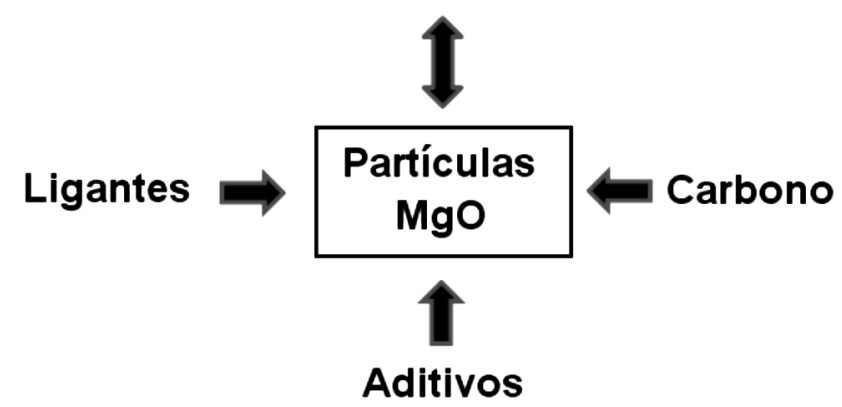

Figura 1: Constituintes em um refratário $\mathrm{MgO}-\mathrm{C}$.

[Figure 1: Constituents of a $\mathrm{MgO}-\mathrm{C}$ refractory.]

empregados na produção/refino de aço. A Fig. 1 exemplifica a constituição de um refratário tipo MgO-C.

A caracterização química, térmica e microestrutural de um refratário magnésia-carbono ou doloma-carbono é bastante difícil e requer um planejamento cuidadoso de testes, incluindo-se o uso de equipamentos caros e o desenvolvimento de metodologias específicas. Isto é devido às diferentes fases presentes, sejam elas elementares (ex: $\mathrm{C}, \mathrm{Si}$, e $\mathrm{Al}$ ), fases de não-óxidos inorgânicos (ex: $\mathrm{SiC})$, fases de óxidos inorgânicos (ex: $\mathrm{MgO}, \mathrm{Al}_{2} \mathrm{O}_{3}, \mathrm{CaO}$ ), fases orgânicas (ligantes) e vários aditivos e impurezas, em ampla distribuição granulométrica. Informações relevantes são mostradas sobre diversas técnicas analíticas necessárias à correta caracterização desses refratários [8]. A microestrutura de um tijolo refratário $\mathrm{MgO}-\mathrm{C}$ curado consiste de partículas grandes ou agregados (maiores que $200 \mu \mathrm{m}$ ), partículas médias e pequenas (menores que $100 \mu \mathrm{m}$ ), que formam a

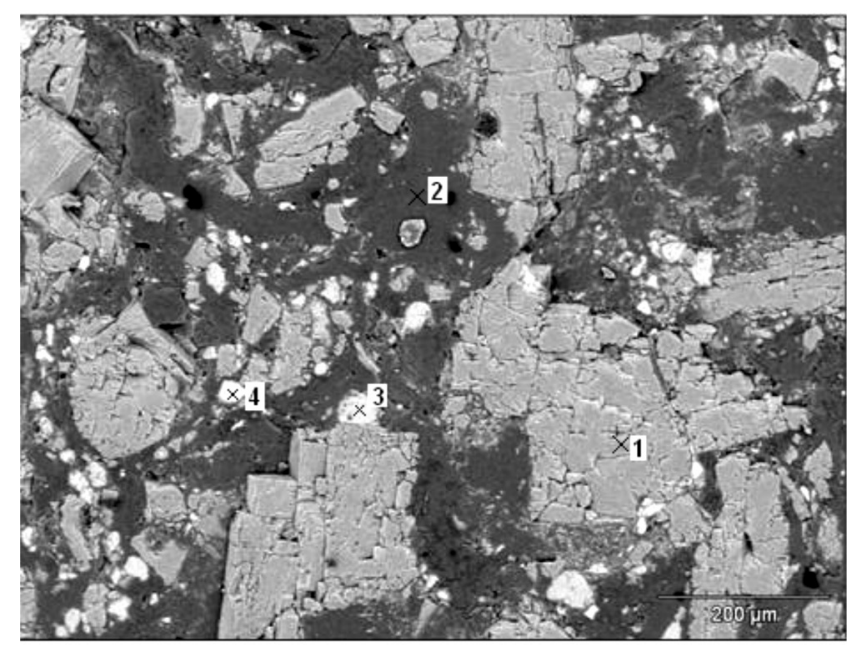

Figura 2: Imagem obtida por microscopia eletrônica de varredura de um tijolo refratário in natura mostrando a distribuição de tamanhos das partículas de magnésia: (1) Agregado de magnésia (grãos eletrofundidos), (2) Matriz ligante de piche, (3 e 4) Presença de antioxidantes.

[Figure 2: Image obtained by scanning electron microscopy of a new firebrick showing the distribution of particle sizes of magnesia: (1) Aggregate magnesia (electrofused grains), (2) Matrix binder pitch, (3 and 4) Presence of antioxidants.] 
Tabela I - Composição química em microssonda EDS dos tijolos refratários de $\mathrm{MgO}-\mathrm{C}$ com antioxidantes (composição química em porcentagem de peso). Pontos de análise referentes à Fig. 2.

[Table I - EDS microprobe chemical composition of the refractory brick of $\mathrm{MgO}-\mathrm{C}$ with antioxidants (chemical composition in weight percentage). Points of analysis relating to Fig. 2.]

\begin{tabular}{cccccc}
\hline Pontos EDS / \% & $\boldsymbol{C}$ & $\boldsymbol{O}$ & $\boldsymbol{M g}$ & $\boldsymbol{A l}$ & $\boldsymbol{S i}$ \\
\hline 1 & & 39,70 & 60,30 & & \\
2 & 100 & & & & \\
3 & & 47,07 & & 52,93 & \\
4 & & 53,26 & & & 46,74 \\
\hline
\end{tabular}

matriz juntamente com um ligante (como resinas ou piche); poros e aditivos antioxidantes.

A Fig. 2 mostra a análise por microscopia eletrônica de varredura (Jeol JSM-5800) e a Tabela I a microanálise química (microssonda de energia dispersada EDS - Noran) de um tijolo MgO-C ligado a piche e curado. Os aspectos mais relevantes da microestrutura como a distribuição de tamanho de partículas, a composição das fases agregados e matriz, a fase ligante e a presença de aditivos são discutidos a seguir.

Os agregados, cuja dimensão pode chegar à escala de milímetros, são os componentes que apresentam maior resistência à fluência e à corrosão. Esta fração grosseira é ainda observada mesmo em caso de corrosão severa. Isto é consequência da maior resistência à dissolução, característica intrínseca à menor área de contato exposta ao meio (menor razão de área superficial por volume). Em geral, quanto maior a pureza e menor a porosidade do agregado, maior será a resistência à corrosão. É importante destacar também que os agregados são formados por partículas pequenas e/ou grãos policristalinos, cuja ligação é formada no processo de calcinação à morte e sinterização ou eletrofusão da matéria-prima. A ligação direta entre grãos (monogrãos ou cristalitos) proveria alta resistência à corrosão. No entanto, as impurezas ou adições intencionais $\left(\mathrm{Fe}_{\mathrm{x}} \mathrm{O}_{\mathrm{y}}, \mathrm{SiO}_{2}, \mathrm{CaO}, \mathrm{Al}_{2} \mathrm{O}_{3}, \mathrm{Cr}_{2} \mathrm{O}_{3}\right)$ formam as chamadas segundas fases, como silicatos, responsáveis pelas ligações entre grãos (e partículas) em menores temperaturas. Atenção especial se dá à razão $\mathrm{CaO} / \mathrm{SiO}_{2}$ que determina a natureza dos minerais que podem se formar. Procura-se manter a razão $\mathrm{CaO} / \mathrm{SiO}_{2}>2$ para se obter fases mais refratárias como silicatos dicálcico e tricálcico nos agregados. Porém, fatores complexos e difíceis de prever como a formação de soluções sólidas (silicatos de $\mathrm{Ca}, \mathrm{Fe}, \mathrm{Mg}$ ) e mesmo o grau de solubilidade do $\mathrm{CaO}$ e FexOy nos cristalitos de $\mathrm{MgO}$, complicam essas generalizações, pois alteram a razão $\mathrm{CaO} /$ $\mathrm{SiO}_{2}$, levando à formação de líquidos nos interstícios [9-11]. Foi concluído que as impurezas do grão de $\mathrm{MgO}$ devem ser menores que $2,5 \%$ e para os refratários de maior qualidade, para aplicações em panelas para aço e BOF, devem ser $<1 \%$ [9]. A razão $\mathrm{CaO} / \mathrm{SiO}_{2}$ preferencialmente $>3$. O percentual total de $\mathrm{SiO}_{2}, \mathrm{Al}_{2} \mathrm{O}_{3}$ e $\mathrm{Fe}_{2} \mathrm{O}_{3}$ deve ser tão baixo quanto possível, no máximo de $0,1-0,2 \%$. Preferencialmente, o óxido de boro $\left(\mathrm{B}_{2} \mathrm{O}_{3}\right)<0,01 \%$. Para outras aplicações essas especificações mudam. $\mathrm{O}$ tamanho de cristalito também é importante, pois maiores tamanhos significam a redução da área superficial e menores quantidades de fases secundárias. Encontram-se produtos refratários com óxido de magnésio sintético, queimado à morte, com cristalitos de 100-200 $\mu \mathrm{m}$. Porém, melhores resultados em termos de resistência à corrosão são obtidos com refratários que contém ao menos parte dos chamados grãos (eletro)fundidos cujo tamanho de cristalito pode chegar a milímetros e os grãos individuais de $\mathrm{MgO}$ podem ser compostos por fragmentos de monocristais de $\mathrm{MgO}$ [12]. A Fig. 3 mostra uma comparação entre as características de agregados de $\mathrm{MgO}$ sinterizados e eletrofundidos, onde observa-se a maior porosidade inter e intragranular dos primeiros.

A Fig. 4 mostra em detalhe um agregado sinterizado. Em relação à corrosão, observa-se que a quantidade de porosidade conectada é acentuada, o que significa uma menor resistência à penetração de escória e, por conseguinte, menor resistência à dissolução. A porosidade em formato esférico é fechada e isolada e por este motivo não favorece tanto à corrosão como a conectada, embora signifique igualmente o aumento de área superficial, assim que à frente de corrosão chegar ao poro. Por outro lado, poros fechados diminuem a fragilidade do agregado.

A matriz é formada por partículas bem menores que os agregados e apresenta normalmente mais impurezas, como óxidos diversos e silicatos (principalmente os de ferro e de cálcio), além de considerável maior porosidade que os agregados, sendo por isso a região que sofre maior corrosão [12]. Normalmente, a corrosão química dos tijolos refratários começa pela penetração da escória através dos poros e, em casos de corrosão severa da matriz, ocorre à remoção/dissolução da matriz, de modo que os agregados fiquem soltos e posteriormente são erodidos do refratário [12-14]. As partículas menores com menor raio de curvatura e formatos irregulares apresentam, intrinsecamente, maior taxa de solubilidade na escória. No entanto, não é possível modificar esse sistema, pois tal fração de tamanho de partículas é necessária ao melhor empacotamento, ou seja, ao

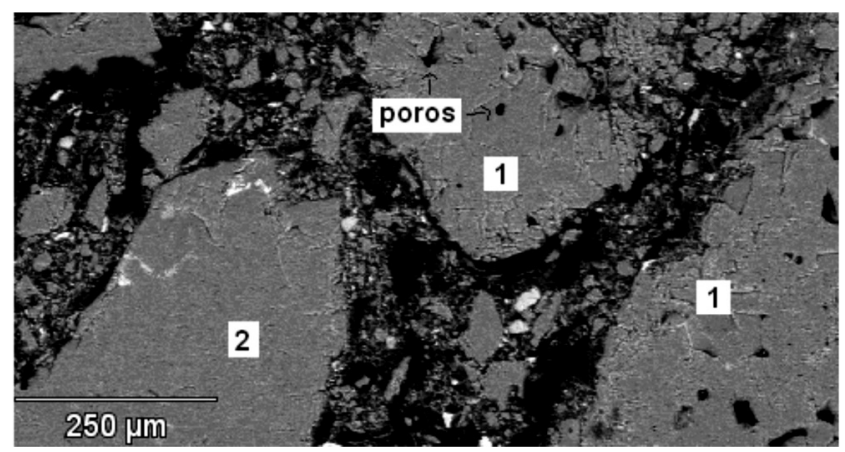

Figura 3: Imagem obtida em MEV. Tijolo refratário in natura mostrando agregados sinterizados (1) e eletrofundidos (2).

[Figure 3: Images obtained by SEM. New firebrick showing sintered aggregates (1) and electrofused (2).] 


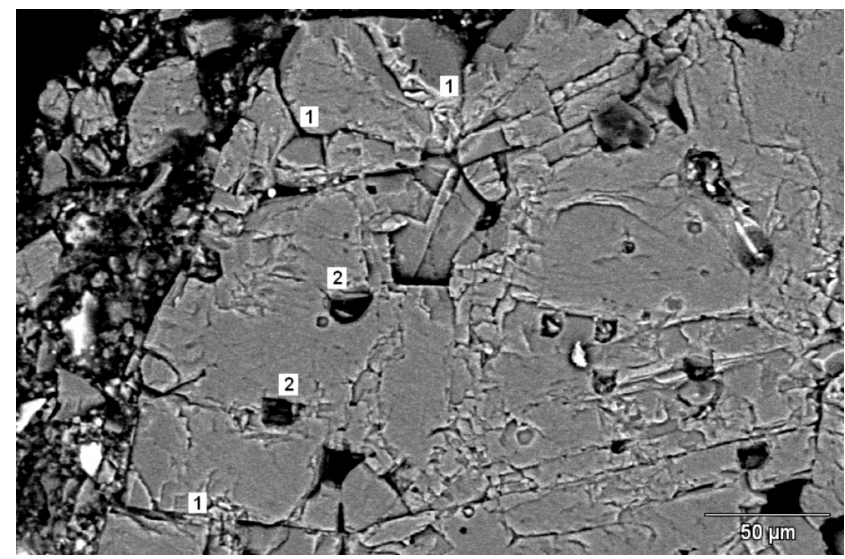

Figura 4: Imagem obtida em MEV. Tijolo refratário in natura mostrando detalhes de agregado sinterizado. (1) poros abertos, (2) poros fechados.

[Figure 4: Images obtained by SEM. New firebrick showing details of sintered aggregate. (1) open pores, (2) closed pores.]

preenchimento do espaço entre agregados, e a própria ligação do conjunto. O carbono presente na matriz vem de uma ou mais fontes, seja na forma amorfa como negro de fumo e carbono pirolítico, este derivado do piche ou de resinas ligantes, ou na forma cristalina de flocos de grafites, podendo este ser classificado também como parte do sistema agregado. Os estudos realizados não chegaram a uma conclusão definitiva sobre qual forma o carbono é mais efetivo [10]. No entanto, o grafite apresenta maior resistência à oxidação $\mathrm{e}$ promove maior condutividade térmica que o carbono amorfo. Estudos recentes mostram dados de redução da oxidação com o aumento de teor de grafite [15]. A função do carbono/ grafite é principalmente evitar a molhabilidade pela escória e aumentar a condutividade térmica. $\mathrm{O}$ aumento desta apresenta duas conseqüências: maior resistência ao choque térmico e o abaixamento da temperatura da escória, aumentando a viscosidade e diminuindo a penetração. Cuidados devem ser tomados com as impurezas no grafite e com as cinzas geradas, pois podem contribuir para formação de eutéticos [10].

É interessante notar que do ponto de vista termodinâmico o uso do carbono constitui um paradoxo, já que esse promove a redução da magnésia:

$$
\mathrm{MgO}(\mathrm{s})+\mathrm{C}(\mathrm{s}) \rightarrow \mathrm{Mg}(\mathrm{g})+\mathrm{CO}(\mathrm{g})
$$

No entanto, o vapor de magnésio ao atingir uma zona de maior pressão parcial de oxigênio reage com este formando uma zona densa de magnésia, a qual previne a penetração de escória [9]. Nos tijolos não queimados (não sinterizados) a ligação entre os componentes é dada pela presença de ligantes inorgânicos, como ácido fosfórico e sulfatos e fosfatos solúveis, e ligantes orgânicos como o piche e resinas, entre estas principalmente as resinas fenólicas [9]. Alguns estudos mostraram que os tijolos resinados apresentaram a formação da zona densa de magnésia mais próxima da face quente do que os ligados por piche, o que levaria a menores níveis de corrosão. No entanto, na presença de $10 \%$ de grafite, essa diferença de comportamento na corrosão desaparece [10]. Diversos estudos apontam para a perda de carbono como o primeiro passo à corrosão, uma vez que a molhagem do refratário pela escória aumenta $[4,10,16,17]$. Na análise de um tijolo $\mathrm{MgO}-\mathrm{C}$ post mortem, observa-se à ausência de carbono na região mais próxima a face quente (Fig. 5 e Tabela II).

Dois mecanismos de oxidação são propostos na literatura [18]: (a) Oxidação indireta em temperaturas maiores que

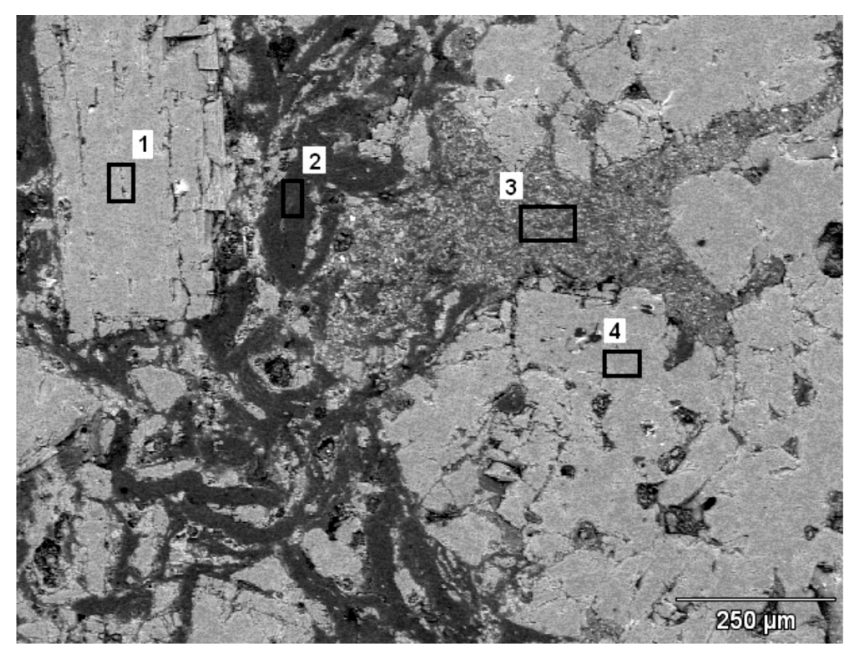

Figura 5: Imagem obtida em MEV. Tijolo refratário post mortem. $(1,4)$ agregados de $\mathrm{MgO}$, (2) Matriz com carbono residual, (3) Matriz sem carbono.

[Figure 5: Images obtained by SEM. Post mortem firebrick. (1, 4) aggregates of $\mathrm{MgO}$, (2) matrix with residual carbon, (3) Matrix without carbon.]

Tabela II - Composição química em microssonda EDS do tijolo refratário de MgO-C com antioxidantes (composição química em porcentagem de peso). Áreas de análise referentes à Fig. 5.

[Table II - EDS microprobe chemical composition of the refractory brick of $\mathrm{MgO}$-C with antioxidants (chemical composition in weight percentage). Areas of analysis relating to Fig. 5.]

\begin{tabular}{cccccccc}
\hline Áreas $\boldsymbol{E D S}$ / \% & $\boldsymbol{C}$ & $\boldsymbol{O}$ & $\boldsymbol{M g}$ & $\boldsymbol{A l}$ & $\boldsymbol{S i}$ & $\boldsymbol{C a}$ & $\boldsymbol{F e}$ \\
\hline 1 & & 39,70 & 60,30 & & & & \\
2 & 26,80 & 72,11 & 1,09 & & & & \\
3 & & 47,47 & 9,90 & 24,57 & 16,00 & 0,62 & 1,44 \\
4 & & 39,63 & 59,92 & & & 0,46 & \\
\hline
\end{tabular}


$1400{ }^{\circ} \mathrm{C}$, como mostrado na equação A. (b) Oxidação direta em temperaturas menores $1400^{\circ} \mathrm{C}$, equação B.

$$
2 \mathrm{C}(\mathrm{s})+\mathrm{O}_{2}(\mathrm{~g}) \rightarrow 2 \mathrm{CO}(\mathrm{g})
$$

A oxidação passa a ser mais significativa a partir de 800 ${ }^{\circ} \mathrm{C}$, como representado na Fig. 6, onde se evidencia uma zona oxidada, com o centro da amostra sem reagir [19]. Isto ressalta também a importância do controle da atmosfera durante o pré-aquecimento ou reaquecimento de panelas, cujas temperaturas de queima de gás chegam a $1200^{\circ} \mathrm{C}[20]$.

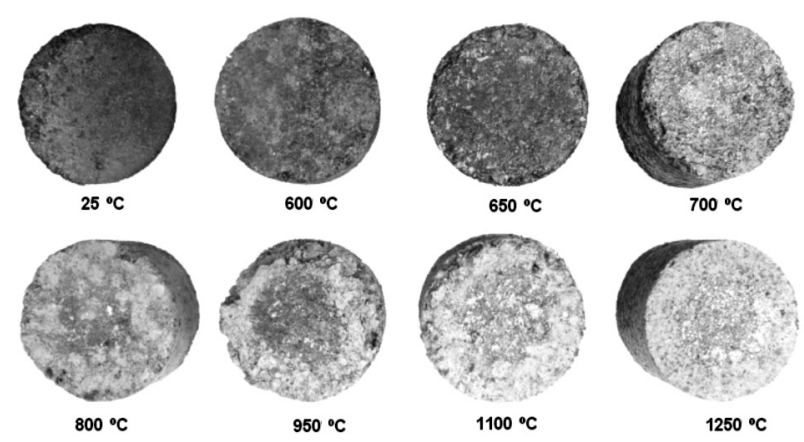

Figura 6: Corpos-de-prova de $\mathrm{MgO}-\mathrm{C}$ após oxidação por $12 \mathrm{~h} \mathrm{em}$ diferentes temperaturas [19].

[Figure 6: $\mathrm{MgO}-\mathrm{C}$ bodies after oxidation for $12 \mathrm{~h}$ at different temperatures [19].]

A oxidação e perda do carbono presente no refratário podem propiciar o aumento da porosidade e, conseqüentemente, a redução da resistência mecânica, maior infiltração de escória e maior penetração de ar e gases do processo. Isto tem consequência direta no aumento da corrosão e erosão do material refratário. Como dito, os antioxidantes são utilizados para atenuar a oxidação do carbono, impedindo diretamente a perda do efeito de redução da molhabilidade da escória, de modo que esta não penetra na capilaridade, o que significa uma menor área de contato.

Os antioxidantes mais utilizados são os pós metálicos de $\mathrm{Al}, \mathrm{Mg}$ e Si. Resumidamente, estes apresentam os seguintes efeitos: redução do $\mathrm{CO}$, o que inibe a oxidação; formação de fases cerâmicas, como $\mathrm{MgAl}_{2} \mathrm{O}_{4}$, aumentando a resistência a quente; facilitar a formação da camada densa de magnésia; fases condensadas, protegendo os flocos de grafites e fechando os poros à penetração de oxigênio. Outros aditivos como os boretos reduzem a oxidação do carbono pela formação de fases líquidas, mas podem, por esse motivo, diminuir a resistência à corrosão e a resistência mecânica a quente. Para alguns autores a presença de $\mathrm{SiC}$ ou $\mathrm{Si}_{3} \mathrm{~N}_{4}$ reduz a corrosão, embora alguns estudos mostrem dados contrários [10]. O $\mathrm{SiC}$ foi o primeiro aditivo utilizado sendo posteriormente suplantado pelos pós metálicos [9]. Ressalva-se que os antioxidantes não atuam diretamente para diminuir a pressão parcial de oxigênio, mas formam fases que criam barreiras à penetração, fechando a porosidade [21]. Este preceito teórico está de acordo com o mostrado na Fig. 5 na região 3, cuja composição se aproxima a de uma fase formada pelos antioxidantes (uma escória teria valores de cálcio bem mais elevados) e, notadamente, fecha a porosidade. Uma revisão detalhada sobre antioxidantes utilizados em refratários contendo carbono pode ser encontrada em [22].

\section{CONCLUSÕES}

Um material para resistir a condições operacionais extremas, como temperatura elevada e corrosão, via de regra possui microestrutura complexa. Diversos aspectos desta microestrutura foram abordados neste trabalho. O desenvolvimento de materiais refratários, assim como a utilização dos mesmos, requer a compreensão desses aspectos microestruturais, de modo a se saber selecionar e aprimorar cada fator que será determinante para se aumentar à vida útil do material em serviço, especificamente, adaptado às condições operacionais de cada indústria.

\section{REFERÊNCIAS}

[1] J. P. Ferreira, Estudo dos desgastes de refratários dolomíticos aplicados em panelas de aço na produção de aços ao carbono, Diss. Mestrado, Universidade Federal do Rio Grande do Sul, RS (2010) 4-12.

[2] Steel Statistics Yearbook 2011 - World Steel Association, disponível em www.worldsteel.org (2011).

[3] W. Q. Casséte, Seminário da Associação Brasileira de Metalurgia (ABM), Refratários para siderurgia, Belo Horizonte, MG (2000) 135-152.

[4] R. A. Mattila, J. P. Vatanen, J. J. Harkki, Scandinavian J. Metallurgy 31 (2002) 241-245.

[5] M. A. L. Braulio, E. W. Zinngrebe, S. R. van der Laan, V. C. Pandolfelli, Ceram. Int. 38 (2012) 1447-1462.

[6] J. Poirier, F. Qafssaoui, J. P. Ildefonse, M. L. Bouchetou, J. Eur. Ceram. Soc. 28 (2008) 1557-1568.

[7] A. P. Luz, V. C. Pandolfelli, Cerâmica 57, 343 (2011) 294-304.

[8] A. H. De Aza, F. J. Valle, P. Ortega, P. Pena, S. De Aza, J. Am. Ceram. Soc. 89, 5 (2006)1704-1708.

[9] R. A. Landy, "Magnesia Refractories", in Refractories Handbook, ed. C. A. Schatcht, Marcel Dekker Inc., New York, EUA (2004) 109.

[10] W. E. Lee, S. Zhang, Int. Mater. Rev. 44, 3 (1999) $77-$ 104.

[11] W. E. Lee, S. Zhang, VII Int. Conf. Molten Slags, Fluxes and Salts, The South African Institute of Mining and Metallurgy (2004).

[12] D. A. Brosnan, "Corrosion of refractories", in Refractories Handbook, ed. Schatcht, C. A., Marcel Dekker Inc., New York, EUA(2004) 39.

[13] A. M. Segadães, Refractários, Universidade de Aveiro, Portugal (1997) 65.

[14] S. Jansson, V. Brabie, P. Jönsson, Ironmaking Steelmaking 5, 2 (2008) 99-107.

[15] B. Hashemi, Z. A. Nemati, M. A. Faghihi-Sani, Ceram. Int. 32 (2006) 313-319.

[16] S. Akhurt, H. D. Leigh, Am. Ceram. Soc. Bull. 82, 5 (2003) 32-40.

[17] S. Camelli, M. Labadie, Int. Feuerfest-Koll. (2006) 30-34. 
[18] S. K. Sadrnezhaad, Z. A. Nemati, S. Mahshid, S. Hosseini, B. Hashemi, J. Am. Ceram. Soc. 90, 2 (2007) 509515.

[19] S. K. Sadrnezhaad, S. Mahshid, B. Hashemi, Z. A. Nemati, J. Am. Ceram. Soc. 89, 4 (2006) 1308-1316.

[20] A. N. C. Lima, R. M. Trommer, A. Zimmer, S. R.
Bragança, J. Boschetti, C. P. Bergmann, Rev. Matéria 13, 3 (2008) 488- 494.

[21] W. E. Lee, R. E. Moore, J. Am. Ceram. Soc. 81, 6 (1998) 1385-1410.

[22] A. P. Luz, V. C. Pandolfelli, Cerâmica 53, 328 (2007) 334-344.

(Rec. 24/08/2011, Rev. 16/02/2012) 